\title{
EVALUATION OF INFORMATION SYSTEMS PROCUREMENT: GOAL AND TASK-DRIVEN APPROACHES
}

\author{
Olegas Vasilecas, Algis Saulis, Saulius Dereškevičius \\ Department of Information Systems, Vilnius Gediminas Technical University \\ Sauletekio al. 11, LT-2040 Vilnius, Lithuania
}

\begin{abstract}
The paper analyses problems of information systems procurement evaluation. Various evaluation systems and strategies used today are discussed. Goal-driven and task-driven evaluation approaches are recognised as the most universal, they enable to set evaluation criteria logically and to receive well-founded results. Details of implementation of proposed evaluation methodology are presented. Quality management problems related with procurement, influence of various constraints, feedback in the acquisition process and other ways to procure the best possible system are described.
\end{abstract}

\section{Introduction}

Enterprises spend huge sums of money for acquisition of information systems (IS). It is the main reason of permanent interest in evaluation of IS efficiency and benefits. The main problem is to define what is to be evaluated, how to evaluate, and when to evaluate. The task is not simple, and separate authors submit different methods to solve it [1], [6], [7]. The main attention is paid to the evaluation of the systems to be developed [12] and already implemented IS [15]. Early evaluation of IS confirms or denies decision on the system development or acquisition. Evaluation of implemented IS shows its actual benefits and drawbacks, assesses degree of the initial decisions realisation.

Early evaluation of IS is actually assessment of the decision to procure IS. Decision may be rational or political, or may include features of both types. Rational decisions use systematic and accurate data, decisions are logically based on the value maximisation upon given constraints [14]. Decisions become uncertain when there are no enough data to validate them. Such a situation is quite possible at early stage. Moreover, rational decisions do not assess qualitative aspects, risk and social factors. Contrarily, political decisions are useful in the situations with limited information and time for decision making [10]. They provide greater flexibility and facilitate decision making. Political decisions do not use mathematical methods, they are based on bargaining among interests. It is difficult to treat political decisions as well founded, but they are inevitable in the situations when rational evaluation is impossible. Combinations of both described decisions types are most widely used.
Available quantitative data create basis for rationality, while uncertainties, risk and social phenomenon are irrational.

Evaluation of implemented IS must be rational because all necessary quantitative data should be available. Evaluation can be expanded including social and organisational qualitative features [5].

Evaluators of IS are persons with different points of view and interests. They may be system owners, managers, developers, users, auditors, researches, etc. Some of them are interested only in the benefit of implemented system, others strive for usage efficiency, the thirds look for following of formal procedures, and the fourths try to get information on possible system improvements. As the result, evaluation criteria vary from hard defined economic and technical to soft users-oriented. Such an evaluation can be treated as interest-driven evaluation. Cost/benefit analysis, which uses rational quantitative methods, is an example of a given type [14]. Narrow viewpoint characterises interest-driven evaluation.

Any evaluation is featured by its scope and available data. Evaluation scope determines width of a viewpoint. Data may restrict possible scope. To evaluate procurement of IS with the widest scope, we must assess all processes from the initial idea on necessary system to the IS implementation. The chain of generalised processes is the following

Goals - Decisions - Actions - Results

If we accept such scheme, goals will define what is to be evaluated, and the evaluation becomes goaldriven. Goals of IS procurement are defined in the strategic plans of the development of information technologies in the organisation. Necessary decisions 
are initiated to implement the goals. The actions that realise decisions ensure procurement and implementation of IS. Operating IS is the final result. The final evaluation must show a degree in which the goals are achieved.

Goal-driven evaluation ensures the widest viewpoint, but not in all situations it is applicable. When goals are not clearly formulated, tasks replace goals in the chain of generalised processes

\section{Tasks - Decisions - Actions - Results}

Tasks define necessary IS, and the evaluation must show a degree in which that tasks are fulfilled. Taskdriven evaluation can be performed in all situations because IS tasks are always reflected in the procurement documentation.

We treat goal-driven and task-driven approaches as the most universal to evaluate procurement of IS. The following sections describe details of the implementation of discussed approaches. Possible evaluation strategies are discussed in Section 2. Section 3 presents analysis of acquisition and evaluation processes. Section 4 describes quantitative evaluation criteria. Finally, Section 5 presents the main conclusions.

\section{IS evaluation strategies}

Goal-driven, task-driven or other approaches determine IS evaluation aims of the highest level. Those aims are to be detailed into lower level tasks. To solve them, evaluator can apply different strategies and methodologies. IS evaluation strategies are widely analysed in [2], they define what to evaluate and how to do it. Generalised evaluation conditions are viewable of two different types:

- Evaluate IS as such means that evaluation is carried out without any involvement from users. Data for such evaluation include systems hardware, software and available IS documentation. How the evaluation is performed depends on the "how-strategy" chosen. The evaluator explores what is possible to do with the system. Evaluation can be applied to separate sub-system.

- Evaluate IS in use means analysis of the system together with a user. Such an analysis is more complicated because of necessity to evaluate interaction of the system and the user. Additional data sources could be interviews of the users, their perceptions and understanding of the system. Evaluation must be performed with fully installed system.

Three types of strategies, with regards on what drives the evaluation, can define how to evaluate:

- Goal-based evaluation means that some goals from the organizational context drive the evaluation [10], [14]. The main task in this case is to measure if predefined goals are fulfilled or not, to what extent and in what ways. Goals determine what to measure. Specific business goals can be used for this purpose. The evaluation is formalrational and mainly quantitative because it concentrates on technical and economic aspects. There are also goals of social and human nature. The fulfillment of such goals can be expressed in qualitative terms. Qualitative approach enriches the quantitative numbers.

- Goal-free evaluation means that no goals are used [11], [14]. Goal-free evaluation is defined as gathering data on a broad array of various actual effects and evaluating the importance of these effects. This strategy is situational driven, it is more interpretative. The aim of interpretive evaluation is to gain a deeper understanding of the nature of what is to be evaluated. The interpretative view treats IS as social systems with embedded technology. The evaluator analyses only the system outcomes and measurable effects. The strategy lets avoid the risk of narrowly stated system objectives and missing important outcomes, it eliminates the perceptual evaluation of goals, it ensures evaluator objectivity and independence.

- Criteria-based evaluation uses some explicit general criteria. The criteria used are derived from specific views or theories. It may be cognitive science and computer science [9], or other. Criteria are not derived from a specific organizational context and are more general applicable. Criteria-based approaches are heuristics, checklists and quality ideals [1]. Specific predefined criteria, IS user interface and interaction between users and system are used as a basis for the evaluation. When criteria are used, it means that focus is set on certain qualities that are important to evaluate. At the same time the rest qualities are de-emphasized.

Six possible combinations of "what to evaluate" and "how to evaluate" appear. Information presented in Table 1 should help to choose the most suitable strategy in various evaluation situations. Strategies discussed can be used in combined ways in different evaluation stages.

\section{Acquisition and evaluation processes}

Procurement cannot be analysed separately without a context of a wider IS acquisition process. We see IS acquisition process as a set of the following stages:

- Analysis of the organisation goals and possibilities of their realisation using IS,

- Decisions on necessary acquisitions based on goals and organisation needs,

- Setting up of the IS requirements specification for IS procurement,

- Planning and execution of the procurement, choosing the best tender,

- Installation of purchases and IS operation, 
- Evaluation of the procurement results.

Timely evaluation of the results of each stage lets control and improve the entire acquisition process and supplies additional data for final IS procurement evaluation.

Goals of the organisation are reflected in its strategic plans and are expressed in generalised manner. IS can stimulate achieving of such goals as increasing of profit, saving of material, financial and human resources, increasing of efficiency and productivity, improving of organisation management, operating conditions and competitive ability.

Decision on IS acquisition should be always based on organisation goals and analysis of its needs, but some situations, such as obsolescence of available technology, favourable situation in a market, or possession of extra funds, can accelerate it. Decision on IS procurement can be rational or political. An evaluator of a given stage should ascertain on adequacy of analysis and validity of the decision.

Table 1. Application of evaluation strategies

\begin{tabular}{|l|l|l|l|}
\hline \multicolumn{1}{|c|}{ Strategy } & \multicolumn{1}{|c|}{ Objectives } & \multicolumn{1}{c|}{ Data sources } & \multicolumn{1}{c|}{ Application field } \\
\hline $\begin{array}{l}\text { Goal-free, } \\
\text { IS as such }\end{array}$ & $\begin{array}{l}\text { To get understanding and } \\
\text { introductory knowledge about } \\
\text { IS }\end{array}$ & IS itself and its documentation & $\begin{array}{l}\text { Introductory study. There are } \\
\text { fewer resources; there are no } \\
\text { users available }\end{array}$ \\
\hline $\begin{array}{l}\text { Goal-based, } \\
\text { IS as such }\end{array}$ & $\begin{array}{l}\text { Analysis of fulfilment of the } \\
\text { desired business goals }\end{array}$ & $\begin{array}{l}\text { IS itself and its documentation, } \\
\text { description of goals, } \\
\text { requirements specification }\end{array}$ & $\begin{array}{l}\text { Strictly defined evaluation is } \\
\text { necessary. There are fewer } \\
\text { resources; there are no users } \\
\text { available }\end{array}$ \\
\hline $\begin{array}{l}\text { Criteria-based, } \\
\text { IS as such }\end{array}$ & $\begin{array}{l}\text { Analysis of the quality of IS } \\
\text { from different perspectives }\end{array}$ & $\begin{array}{l}\text { IS itself and its documentation, } \\
\text { description of criteria }\end{array}$ & $\begin{array}{l}\text { A focused evaluation is } \\
\text { wanted. There are fewer } \\
\text { resources; there are no users } \\
\text { available }\end{array}$ \\
\hline $\begin{array}{l}\text { Goal-free, } \\
\text { IS in use }\end{array}$ & $\begin{array}{l}\text { To get more wide } \\
\text { understanding of IS, its role } \\
\text { in the business, its social and } \\
\text { organisational consequences }\end{array}$ & $\begin{array}{l}\text { IS itself and its documentation, } \\
\text { analysis of interactions, users } \\
\text { perceptions of IS }\end{array}$ & $\begin{array}{l}\text { Thoroughly evaluation is } \\
\text { desired }\end{array}$ \\
\hline $\begin{array}{l}\text { Goal-based, } \\
\text { IS in use } \\
\text { desired business goals; } \\
\text { positive and negative } \\
\text { consequences, and impact of } \\
\text { IS for the business }\end{array}$ & $\begin{array}{l}\text { IS itself and its documentation, } \\
\text { goal description, requirement } \\
\text { specifications, observations of } \\
\text { interactions, users perceptions of } \\
\text { IS }\end{array}$ & $\begin{array}{l}\text { A focused evaluation is } \\
\text { wanted; there are more } \\
\text { resources }\end{array}$ \\
\hline $\begin{array}{l}\text { Criteria-based, } \\
\text { IS in use }\end{array}$ & $\begin{array}{l}\text { To get a deeper and wider } \\
\text { perceptions of IS }\end{array}$ & $\begin{array}{l}\text { IS itself and its documentation, } \\
\text { descriptions of criteria, } \\
\text { observations of interactions, } \\
\text { users perceptions of IS }\end{array}$ & $\begin{array}{l}\text { Thoroughly evaluation, } \\
\text { depending on the chosen set of } \\
\text { criteria, is desired; there are } \\
\text { more resources }\end{array}$ \\
\hline
\end{tabular}

Table 2. Acquisition stages and evaluation characteristics

\begin{tabular}{|c|c|c|c|}
\hline \multirow{2}{*}{$\begin{array}{l}\text { Acquisition } \\
\text { stage }\end{array}$} & \multicolumn{3}{|c|}{ Evaluation } \\
\hline & Goals & Criteria & Viewpoint \\
\hline $\begin{array}{l}\text { Analysis of } \\
\text { needs }\end{array}$ & $\begin{array}{l}\text { To make assurance on objectivity of } \\
\text { needs and their priorities }\end{array}$ & $\begin{array}{l}\text { Scope and depth of analysis, foresight } \\
\text { and prognostication of needs }\end{array}$ & Social, economic \\
\hline $\begin{array}{l}\text { Definition of } \\
\text { requirements }\end{array}$ & $\begin{array}{l}\text { To define the level of adequacy of } \\
\text { needs and requirements }\end{array}$ & $\begin{array}{l}\text { Validity, particularity, fullness and } \\
\text { sufficiency of the requirements }\end{array}$ & $\begin{array}{l}\text { Technical, } \\
\text { economic }\end{array}$ \\
\hline $\begin{array}{l}\text { Procurement } \\
\text { process }\end{array}$ & $\begin{array}{l}\text { To define the level of adequacy of } \\
\text { requirements and purchases; to make } \\
\text { assurance on the best choice }\end{array}$ & $\begin{array}{l}\text { Quality of bidding documents, } \\
\text { assessment of bids and contract }\end{array}$ & $\begin{array}{l}\text { Economic, } \\
\text { technical, } \\
\text { bureaucratic }\end{array}$ \\
\hline IS operation & $\begin{array}{l}\text { To assess efficiency of purchases and } \\
\text { possibilities to enlarge it }\end{array}$ & $\begin{array}{l}\text { Quality of exploitation and mainte- } \\
\text { nance, users satisfaction, real benefits }\end{array}$ & Social, technical \\
\hline $\begin{array}{l}\text { Final } \\
\text { evaluation }\end{array}$ & $\begin{array}{l}\text { To assess the level of adequacy of } \\
\text { initial needs and procured system }\end{array}$ & $\begin{array}{l}\text { Social, organisational and managerial } \\
\text { outcomes, economic efficiency }\end{array}$ & Social, economic \\
\hline
\end{tabular}

A requirement specification is the main document that describes necessary IS. It defines minimal technical parameters and sets limits of possible price. Requirement specification reflects organisation needs and its possibilities. Evaluation of the stage must approve or deny this. If the evaluator finds IS requirement specification does not fully conform to the organisation needs, it should be possible to use feedback and correct the specification.

Procurement process includes a few steps: preparing of bid documents, organising of bids, choosing of the best tender, setting-up and fulfilment of contract. When procurement is performed following the Law of the Republic of Lithuania on Public 
Procurement [8] that is obligatory for state and local authorities or other legal persons, various additional bureaucratic constraints appear. Evaluation of the stage must assess quality of bid documents and conformance of them and of overall process to the Law on Public Procurement. The selected and procured IS must satisfy the requirement specification and be the best among available choices. Procurement process is the most responsible stage of the acquisition process because of absence a feedback in this stage. Evaluation of the stage cannot improve results of the stage.

It is impossible to evaluate procured IS immediately because all features of the system emerge only after some time of its operation. To evaluate operation stage, one must assess users and personal preparation, the system operation and its maintenance. There are very limited possibilities of a feedback in a given stage. You cannot change IS, but you can improve its maintenance or train the users.

The final evaluation of the procurement must show in what degree the procured IS conforms to the organisation needs and in what extent it stimulates realisation of primary goals, what are anticipated and unexpected social and organisational changes, what real benefits were obtained. At the same way, the evaluation can show what may be better accomplished in each acquisition stage.

Summarised features of separate IS acquisition stages are presented in Table 2. Figure 1 depicts the proposed complex scheme of IS acquisition and evaluation stages.

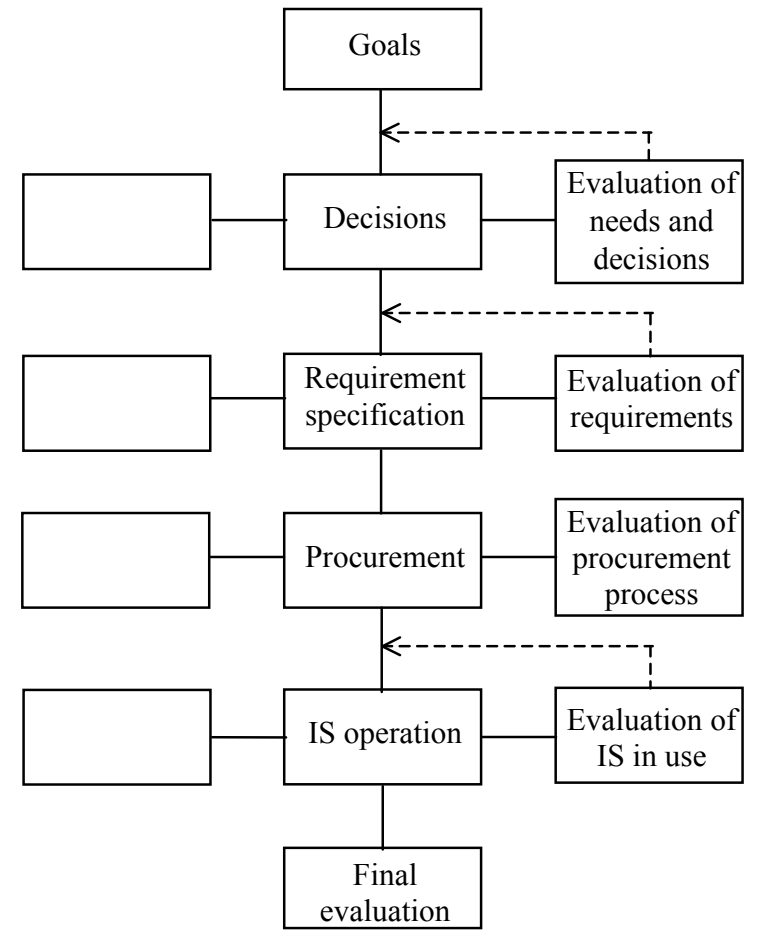

Figure 1. IS acquisition and evaluation process

The task-driven approach is to be applied when the evaluator has not data on goals, or when initial stages of acquisition process do not exist because of political decision on IS procurement. Evaluation of the requirement specification must help to avoid inconsistent and/or conflicting demands in such case. Evaluations of procurement process and operation retain all just described features. The final evaluation should emphasise a degree the procured IS conforms to the declared tasks, and real benefits for organisation and users.

\section{Criteria of quality evaluation}

Quality of IS depends on various groups of criteria - technical, economical, social, organisational, etc. [3], [4]. Some of them are rational and quantitative, the rest can be evaluated only qualitatively. To create a quality measure, we must use unique generalised metrics that can include various types of generic criteria. We propose to use generalised criteria for different metrics that can be estimated in a four-grade scale:

0 - does no satisfy requirements;

1 - not full satisfy requirements;

2 - satisfy requirements;

3 - slightly exceed requirements;

4 - distinctly exceed requirements.

The criteria offered are suitable in the situations when IS to be evaluated is compared with some standard or specification. Criteria may be more accurate, if more grades are used, e.g. 10.

Quality of IS, which is evaluated using various generalised criteria of different importance that are located in separate groups, can be assessed using formula

$$
Q=\sum_{j=1}^{n} w_{j} \sum_{i=1}^{k j} s_{j i} w_{j i},
$$

where $w_{\mathrm{j}}$ - weight of the group $j ; s_{\mathrm{ji}}-$ value of the $i$ th criterion in the group $j ; w_{\mathrm{ji}}$ - weight of the $i$-th criterion in the group $j ; n$ - number of criteria groups; $k j$ - number of evaluated criteria in the group $j$.

Quality function Q is usually supplemented with constraints, which assess the lowest quality requirements and financial possibilities

$$
\left.\begin{array}{l}
s_{j i} \geq s_{\text {minji }}, \\
C \leq C_{\text {max }},
\end{array}\right\}
$$

where $S_{\text {minji }}-$ the lowest acceptable value of the criterion $S_{j i} ; C$ - price of IS; $C_{\max }-$ the highest acceptable price.

Typical values of the marginal criteria $S_{\text {minji }}=2$ in a four-grade scale.

There are three strategies of the best choice. The first seeks to maximize quality

$$
\mathrm{Q} \rightarrow \max \text {; }
$$

the second strives to minimize price

$$
\mathrm{C} \rightarrow \min ,
$$

and the third combines the first two. 
We assess the first strategy best. Information technologies are constantly improved. IS, which features exceed today requirements, can be used longer time without obsolescence. Flexible constraint and requirement system can be applied to find a proposal with the highest quality.

The second strategy is used in the procurement process that follows the Law on Public Procurement [8]. All requirements here are strictly defined in advance without any possibility to correct them. The best proposal is the cheapest one. Application of this strategy to the procurement of IS is disputable.

The third strategy is implemented in the procurement process that follows methodology of the World Bank [13]. Bid score $B$, which assesses the bid price and the technical merits, is calculated for each evaluated bid using the following formula

$$
B=\frac{C_{\min }}{C} W+\frac{Q}{Q_{\max }}(1-W),
$$

where $C$ - evaluated bid price, $C_{\min }$ - the lowest of all evaluated bid prices among responsive bids; $Q$ - the total quality (1) awarded to the bid; $Q_{\max }$ - the quality achieved by the bid that was scored highest; $W-$ weight for price.

Theoretical values of weight for price can be 0 $<W<1$, recommended values are $0.5<W<1$. This means that price should be evaluated higher. The best bid has the highest bid score value.

\section{Conclusions}

Presented analysis of IS evaluation approaches shows possibility to apply them to the evaluation of IS procurement. Goal-driven approach is recognised as the most universal. It enables to use logically well founded evaluation criteria of wide scope. Task-driven evaluation can be used as well, but its viewpoint is narrower.

To achieve well founded results, entire IS acquisition process must be taken into account, and separate stages of it should be evaluated. Evaluation of each stage lets find a reason of unachieved primary goals, or can show a way to achieve the goals more efficiently. Timely evaluation of a stage lets use feedback and improves the results, contributing quality control of the acquisition process. Efficiency of a feedback is the highest during initial stages of the acquisition process.

IS quality function, which enables comparison of separate systems, is proposed. The function enables to use quantitative and qualitative criteria with necessary accuracy. Each criterion is supplied with weight that reflects importance of a given criterion. Quality function is totally dependent on the IS requirements, but there are no hard defined methods to set unique relationship between the requirements and parameters of the function. Uncertainties of setting of some function parameters include the element of subjectivity into IS quality evaluation.

Three ways to choose the best proposal during IS procurement process are analysed. They are based on the optimisation of quality, price or both of them. Quality maximisation is treated as the best choice. Public procurement process of the Republic of Lithuania supports price minimisation, whereas World Bank process supports hybrid optimisation. Public procurement process imposes bureaucratic constraints that hardly restrain procurement operations and limit possibilities to select the best choice.

Free procurement process has many advantages. The process can use informal procedures that ensure necessary flexibility. Evaluation methodology can be adjusted to the real situation, and actually the best system can be procured.

\section{References}

[1] S. Cronholm, G. Goldkuhl. Actable Information Systems - Quality Ideals Put Into Practice. M. Kirikova et al. (Eds.), Information System Development: Advances in Methodologies, Components, and Management, Kluwer Academic/Plenum Publishers, 2002, 135-146.

[2] S. Cronholm, G. Goldkuhl. Strategies for Information Systems Evaluation - Six Generic Types. Electronic Journal of Information Systems Evaluation, 6(2), 2003, 65-74, http://www.ejise.com/volume6-issue2/ issue2-art8.htm .

[3] R. P. Dameri. Using the Balanced Scorecard to Evaluate ICT Investments in Non profit Organisations. Electronic Journal of Information Systems Evaluation, $8(2), 2005$, 107-114, http://www.ejise.com/volume8/v8-iss-2/v8-i2-art3.htm.

[4] G. Fitzgerald. Evaluating information systems projects: a multidimensional approach. Journal of Information Technology, Vol.13, 1998, 15-27.

[5] E. J. Garrity, G. L. Sanders. Information Systems Success Measurement. Idea Group Publishing, 1998.

[6] W. Van Grembergen. Information Technology Evaluation Methods \& Management. Idea Group Publishing, 2001.

[7] R. Hirschheim, S. Smithson. Evaluation of Information Systems. L. Willcocks \& S. Lester (Eds.), Beyond the IT productivity paradox, West Sussex, UK: John Wiley \& Sons Ltd., 1999, 381-409.

[8] Law of the Republic of Lithuania on Public Procurement, 2002, http://www.vpt.lt/admin/uploaded/ lawonP.pdf.

[9] J. Nielsen. Usability Engineering. Academic Press, San Diego, California, 1993.

[10] M. Q. Patton. Qualitative Research and Evaluation Methods. Sage, London, 2002.

[11] D. Rameneyi, M. Sherwood-Smith. Maximize Information Systems Value by Continuous Participate Evaluation. Logistics Information management, 12(1/2), 1999, 14-31.

[12] T.J.W. Renkema, E.W. Berghout. Methodologies for information system investment evaluation at the proposal stage: a comparative view. Information and Software Technology, 39(1), 1997, 1-13. 
[13] Standard Bidding Documents. Supply and Installation of Information Systems Two-Stage Bidding. The World Bank, 2003, http://www.worldbank.org/ itprocurementforum

[14] G. Walsham. Interpreting Information Systems in Organizations. Wiley \& Sons, 1993.
[15] R. Weber. Information systems control and audit. Prentice Hall, Upper Saddle River, NJ, 1999.

Received May 2006. 